\title{
Water condensation system based on thermoelectric coller using solar energy
}

\author{
A. N. Abirami ${ }^{1}$, C. R. Balamurugan' ${ }^{2}$ D. Meena $^{3}$ \\ ${ }^{1}$ Department of EEE, PERI Institute of Technology, India \\ ${ }^{2}$ Department of EEE, Karpagam College of Engineering, India \\ ${ }^{3}$ Department of EEE, Krishnasamy College of Engineering and Technology, India
}

\begin{tabular}{|c|c|}
\hline Article Info & ABSTRACT \\
\hline Article history: & The main objective of the paper is to develop a water condensation system \\
\hline Received Apr 22, 2019 & based on thermoelectric cooler using solar Energy to convert atmospheric \\
\hline Revised Feb 11, 2020 & extended further in future - For large scale implementation, RO and UV \\
\hline Accepted Apr 3, 2020 & $\begin{array}{l}\text { water filter can be used for producing such water that meets the standard of } \\
\text { WHO and BIS easily. Peltier device has many types of models which are }\end{array}$ \\
\hline Keywords: & $\begin{array}{l}\text { much efficient than TEC1. Those can be used. As the paper aims at } \\
\text { producing water from atmosphere and keeping this device handy, large sized }\end{array}$ \\
\hline BIS & scrubbers are not used for better air filtration. Scrubbers can remove all \\
\hline Condensation & $\begin{array}{l}\text { the oxides from the air. For large implementation it can be handled. } \\
\text { The concept of this paper can also be used as a better alternative in }\end{array}$ \\
\hline RO & refrigeration science against conventional systems. It can also be observed in \\
\hline UV & $\begin{array}{l}\text { this way i.e. the usage of such low power semiconductor devices are } \\
\text { indicating towards more prominent evolution of cooling engineering that is } \\
\text { going to alter the whole scenario and myths about the power consumption of } \\
\text { refrigeration science. Thus in near future we will be able to use such devices } \\
\text { that are now limited within the paper. }\end{array}$ \\
\hline
\end{tabular}

This is an open access article under the CC BY-SA license.

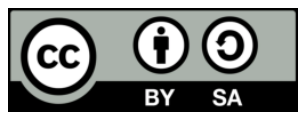

Corresponding Author:

C. R. Balamurugan,

Department of EEE,

Karpagam College of Enigneering,

Myleripalayam Village, Othakkal Mandapam, Tamil Nadu, 641032, India.

Email: crbalain2010@gmail.com

\section{INTRODUCTION}

The air in the atmosphere contains at least a little water. On hot, muggy days, the air feels thick and uncomfortable because it's saturated with moisture. Getting access to fresh water can be difficult in some of the hottest parts of the world. Despite the fact that heat and humidity persist at levels that would seem to invite daily showers, a lack of infrastructure makes it extremely difficult for far-flung communities to gain access to reliable supplies of water. Water generators, also known as water makers, harvest the moisture suspended in humidity air [1]. Within those amounts almost $30 \%$ of water is wasted. This amount of water can be used by implementing a device like Atmospheric Water Generator. They use one of two basic methods. The most common employs technology similar to another appliance in your home, your air conditioner. Warm air passes over a set of coils that are chilled using refrigerant. Because cool air can't hold as much water vapor as warm air, the cold air leaves behind condensation that's routed to a drain or pan for disposal. In a water generator, the goal isn't to cool the air to make interior rooms more comfortable. The goal is to reclaim that condensation, filter it, and then store it in a carafe or other holding tank. 
The reclaimed water is filtered a number of times to take out airborne particles and bacteria as part of the process. If the water sits in the reservoir for longer than a day or so, it's filtered again to keep it fresh and clean. This type of water generator is the most popular for domestic use. The technology is well known and understood. Air conditioners, refrigerators and dehumidifiers all use it to one degree or another. It can be an energy hog, though. Cooling-style water generators rely on compressed refrigerant cycling through the system with the help of a compressor, condenser, a pump and a fan. Some domestic water generator manufacturers claim the energy consumption is similar to running a desktop computer or small space heater in your home. The extraction [2] of atmospheric water may not be free of cost, because significant input of energy is required to drive some AWG processes. Certain traditional AWG methods are completely passive, relying on natural temperature differences, and requiring no external energy source. Research has also developed AWG technologies to produce useful yields of water at a reduced (but non-zero) energy cost. The device uses the principle of latent heat to convert water vapor molecules into water droplets.

In many countries like India, there are many places which are situated in temperate region; there are desert, rain forest areas and even flooded areas where atmospheric humidity is eminent. But resources of water are limited. Here, the goal is to obtain that specific temperature practically or experimentally to condense water with the help of some electronics devices. So, this paper will be helping to extend the applications of such devices further in the near future. According to previous knowledge, we know that the temperature require to condense water is known as dew point temperature. Here, the goal is to obtain that specific temperature practically or experimentally to condense water with the help of some electronics devices.

\section{RESEARCH METHODS}

The aim of the experiment conducted by the authors of this paper was to obtain a specific temperature practically or experimentally to condense water with the help of some electronics devices. The setup made use of a thermoelectric peltier couple (TEC) [3, 4], whose main purpose was to create the environment of condensing water to dew point. The condensed water could be collected to use for drinking purpose and various other uses. The apparatus consisted of a solar cell unit with an output of $12 \mathrm{~V}$ with the maximum output power of $120 \mathrm{~W}$, which is able to supply enough power to run three $40 \mathrm{~W}$ (3.5 A) Peltier coolers (TEC) connected in parallel. The Peltier device has a dimension of $4 \times 4 \times 0.8 \mathrm{~cm}$. The maximum temperature difference $(\Delta \mathrm{T})$ of $87^{\circ} \mathrm{C}$. A $3000 \mathrm{rpm}, 15 \mathrm{x} 15 \mathrm{~cm}$ (size of TEC) fan that is capable of producing airflow of at most $500 \mathrm{cfm}$ was used for circulation of the air. The heat sinks [5] used were made of aluminium and anodized Refrigeration can be achieved by many methods. Some of these are discussed in Figure 1.

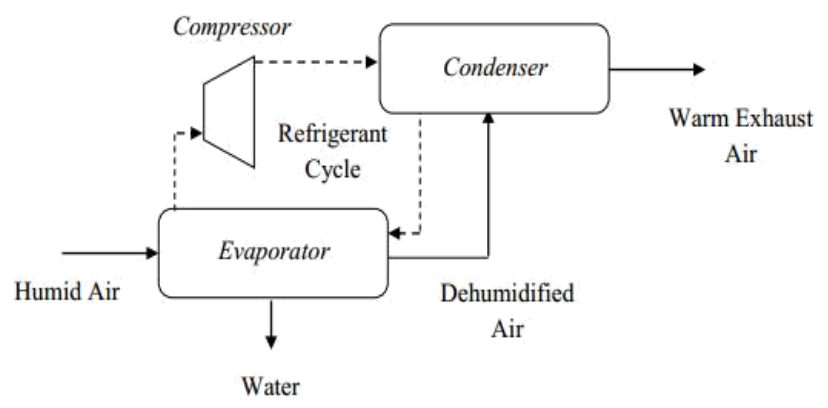

Figure 1. Dehumidification by refrigeration cycle

\subsection{Vapour compression method}

Vapour-compression refrigeration is the most widely used method for air-conditioning in today's world. The vapour-compression consists of a circulating liquid refrigerant as the medium which absorbs and removes heat from the space to be cooled and subsequently rejects that heat to the atmosphere. Figure 2 depicts a single-stage vapour-compression system. Basically the system has four components: a compressor, a condenser, a thermal expansion valve and an evaporator. Circulating refrigerant enters the compressor as 
saturated vapour and is compressed. This results in high pressure which in turn is responsible for higher temperature. The compressed vapour then comes out as superheated vapour and attains a temperature and pressure at which condensation can take place with the help of cooling water or cooling air. That hot vapour is passed through a condenser where it is cooled and condensed [6]. This is where the circulating refrigerant rejects heat from the system. The condensed liquid refrigerant known as saturated liquid is next passed through an expansion valve where there is a sudden drop in pressure. This results in the adiabatic flash evaporation of the liquid refrigerant. The Joule-Thomson effect as it is called lowers the temperature of the liquid and vapour refrigerant mixture which makes it colder than the temperature to be achieved (temperature of the enclosed space). The cold mixture is passed through the coils in the evaporator. A fan circulates the warm air in the enclosed space across the coils carrying the cold refrigerant liquid and vapour mixture. That warm air evaporates the liquid part of the cold refrigerant and at the same time, the circulating air is cooled and as a result it lowers the temperature of the enclosed space to the temperature to be achieved. The circulating refrigerant absorbs and removes heat from the evaporator which is then rejected in the condenser and transferred by the water or air used in the condenser. For the completion of the refrigeration cycle [7], the refrigerant vapour coming out of the evaporator which is again a saturated vapour is returned back into the compressor.

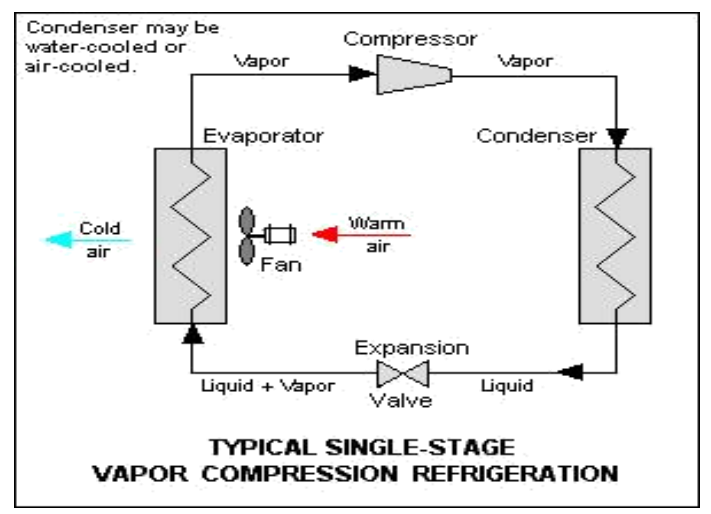

Figure 2. Vapour compression refrigeration cycle

\subsection{Thermodynamic analysis of the system}

The thermodynamics [8] of the vapour compression cycle can be studied with the help of a temperature versus entropy diagram as shown in Figure 3. At point 1 as shown in the Figure 3, the circulating refrigerant enters the compressor as a saturated vapour. From point 1 to point 2 , there is compression of the circulating refrigerant at constant entropy and it comes out of the compressor as superheated vapour. Between point 2 and point 3, the vapour travels through the condenser where there is removal of the superheat by cooling the vapour. From point 3 to point 4 , the vapour travels through the rest 3 of the condenser and thereby resulting in a saturated liquid. This process occurs at constant pressure.

From point 4 to 5 , the saturated liquid refrigerant is routed through the expansion valve resulting in a sudden drop of pressure. That process is responsible for adiabatic flash evaporation and auto-refrigeration of a portion of the liquid which is known as Joule Thomson effect. The adiabatic flash evaporation process occurs at constant enthalpy.

From point 5 to 1 , the cold refrigerant which is in a partially vaporised state is routed through the coils present in the evaporator which is responsible for its complete vaporisation by the warm air that is circulated by a fan present in the evaporator. The evaporator works at constant pressure (isobaric) and boils of all available liquid thereby superheating the liquid and vapour mixture of refrigerant. The resulting refrigerant vapour then flows back to the compressor inlet at point 1 thereby completing the thermodynamic cycle.

It should be noted that the above representation of the thermodynamic cycle does not take into account real world irreversibility like frictional pressure drop, slight internal irreversibility during the compression of the refrigerant vapour and non-ideal gas behaviour. Hence, the above idea simply represents an ideal vapour compression refrigeration cycle. 


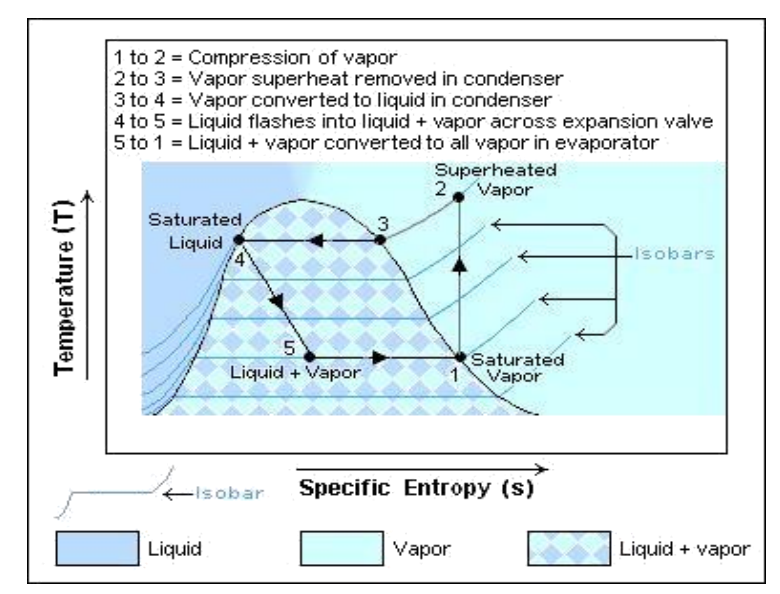

Figure 3. T-S plot of vapour compression refrigeration cycle

\subsection{Refrigerant}

After the introduction of the Montreal Protocol in the year 1987 all the parties agreed to phase out the dangerous ozone depleting refrigerants like CFCs which is one of the most crucial item of a vapour compression refrigeration system. Thus there is a gradual shift from the CFCs to the HCFCs with the motive of saving our ozone layer. Now a days a lot of research is being carried out to explore environment friendly refrigerants, supercritical carbon dioxide known as R-744 being one of them, which have same efficiencies as compared to existing CFC and HFC based refrigerants, and have many orders of magnitude lower global warming potential.

\subsection{Dehumidification by liquid desiccant method}

A desiccant is a hygroscopic substance that induces or sustains a state of dryness (desiccation) in its vicinity. Commonly encountered pre-packaged desiccants are solids that absorb water. Wet desiccation is a process where a brine solution is exposed to humid air in order to absorb water vapour from that air [9]. The solution is then sent into a regenerator where the water vapour is extracted from the solution 2 . This method has grown in popularity because of its efficiency and the ease with which it can be adapted to renewable energy, particularly solar. Figure 6 is a basic representation of this approach.

A primary advantage to this approach is that the desiccant accomplishes the most difficult part of dehumidification, extracting the water from the air, without a direct expenditure of energy. The problem is thus recast into terms of regenerating the desiccant and capturing the resultant water. The main disadvantage of wet desiccation is the complexity that is introduced, both in terms of system and materials.

\section{BLOCK DIAGRAM}

Modern technology makes garments become smart. Weather garments are necessary for people who are exposed to cold and hot environments. It is possible for people to protect their vital organs against cold and hard stresses in indoor and outdoor environments by improving the functionality of garments. Such a system is expected to reduce heat and cold related stresses, reduce fatigue and lead to a safer working environment. The current technological solutions made the people thermally comfortable such as air conditioning and heating units.

But these solutions give comfort only in their dwellings such as homes and cars etc. These are not personal mobility solutions. The main objective of this paper is to create a comfortable environment for the user with in an enclosed space of small proximity and also provides comfort, practicality and mobility.

The suits such as either heating or cooling suits that are available in the market are in high cost. None of them provide dual functionality such as either heating or cooling. The proposed solution allows the dual functionality. Figure 4 shows block diagram and Figure 5 shows circuit diagram of modern technology. 


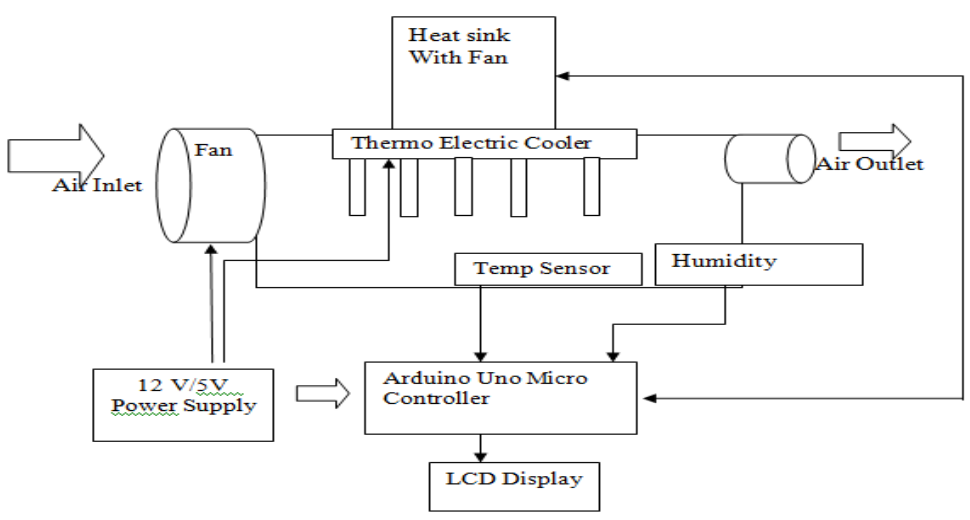

Figure 4. Block diagram

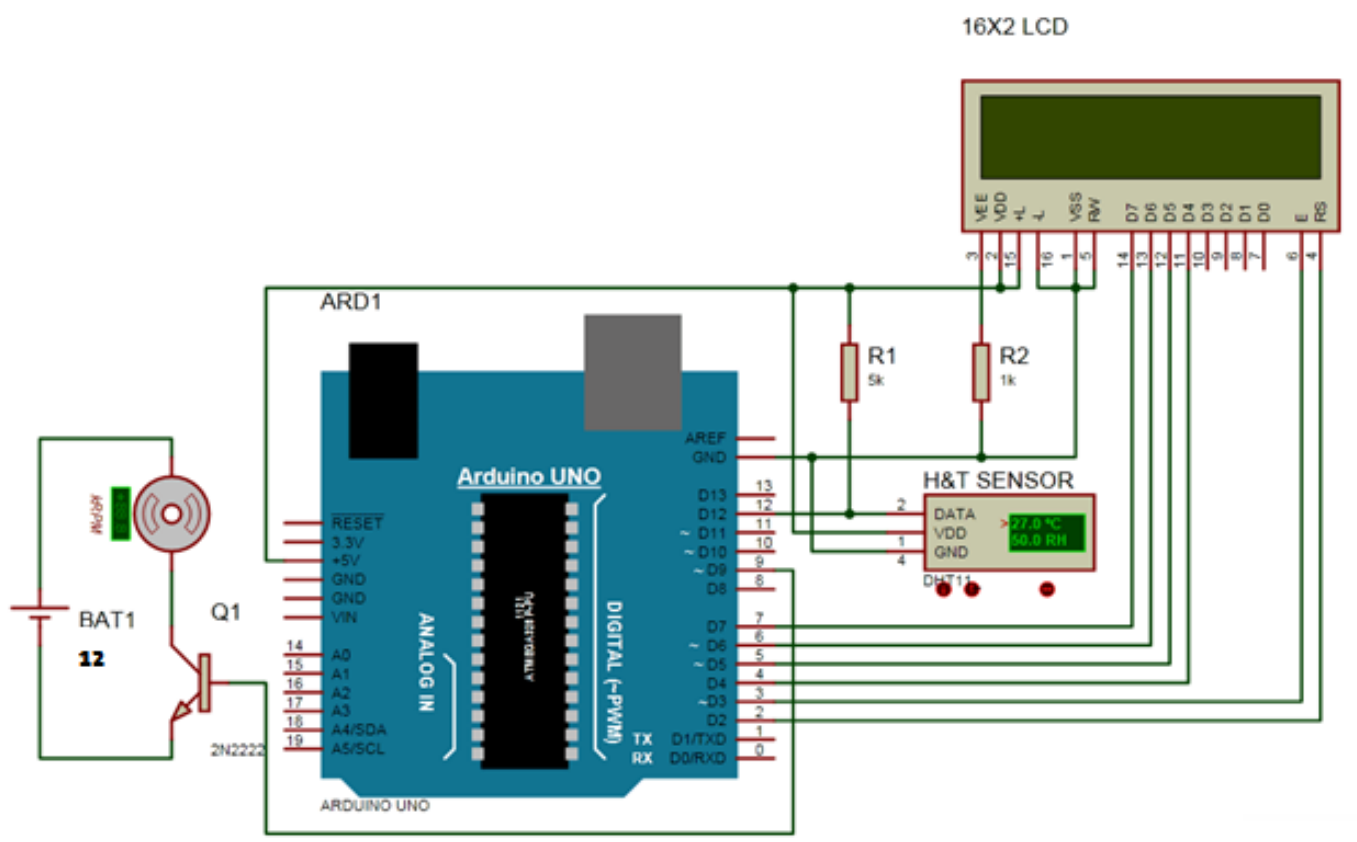

Figure 5. Circuit diagram

\subsection{Proposed method}

The proposed work is Temperature programmable suit by using Arduino Uno and peltier cooler. This system is based on liquid cooling and heating suit. This suit will use tubes to circulate the water throughout vest and have a heat exchanger that recools and recycled water using thermoelectric cooler which was attached to the suit. The heart of this circuit is microcontroller. The code for the microcontroller is programmed to measure the internal and external temperature of the suit and a push button has been added to control the internal temperature of the suit. The main objective of this suit is creating the most comfortable thermal environment for the user and measuring the internal temperature of the suit. The heating and cooling of the suit is done by distributing the water through the suit with the help of pipes, peltier cooler and heat exchanger.

\subsection{Hardware implementation}

The hardware implementation is a microcontroller based system. The hardware implementation of the proposed system The heart of the circuit is microcontroller. The microcontroller controls the all inputs and outputs of the circuit. It heats and cools one side of TECs by using a relay circuit that is enabled and controlled by a rotatory variable resistor. The voltage across this variable resistor is used to pulse width 
modulate the signal to the relay through software, allowing the user to adjust the gradient temperature that TECs generate. The water reservoir is placed on the TEC. The TEC is will be attached to the heat sink. The most pivotal part of this heating/cooling of the suit is performed by the TEC-12706. The thermoelectric cooler is an interesting device that allows the dual functionality such as heating and cooling simultaneously. The heart of the circuit is microcontroller. The microcontroller controls the all inputs and outputs of the circuit. It heats and cools one side of TECs by using a relay circuit that is enabled and controlled by a rotatory variable resistor. The voltage across this variable resistor is used to pulse width modulate the signal to the relay through software, allowing the user to adjust the gradient temperature that TECs generate. The water reservoir is placed on the TEC. The TEC is will be attached to the heat sink. The most pivotal part of this heating/cooling of the suit is performed by the TEC-12706. The thermoelectric cooler is an interesting device that allows the dual functionality such as heating and cooling simultaneously. The thermoelectric cooler (TEC) is also called as peltier cooler. The peltier cooler $[10,11]$ is a solid state heat pump which uses the peltier effect to move heat. Thermoelectric cooler were selected with a maximum operating voltage of $16.4 \mathrm{~V}$ and 6.4Amp. It releases all heat from the hot side of the thermoelectric device. Hence the water in the reservoir becomes cool and the motor was needed to push the water throughout the cooling vest. This cooled water will circulate throughout the vest with the help of pipes that was attached on the suit. This system can be realized byusing thermo electric effect, microcontroller technology and a bit of ingenuity.

The Arduino Uno is a microcontroller on a circuit board based on Atmega328. It has 14 digital input and output pins in which 6 can be used as PWM outputs. It also has 6 analog inputs, a USB connection, a power jack, a 16MHZ ceramic resonator, an ICSP header and a reset button. The Arduino Uno has Flash memory is $32 \mathrm{~KB}$,SRAM is $2 \mathrm{~KB}$, EEPROM is $1 \mathrm{~KB}$ and the Clock speed is $16 \mathrm{mhz}$. The Arduino Uno can be powered through the USB association or with an external power supply. The power source is chosen naturally

Thermo electric cooler/Heater: This application requires the development of a system that requires both warming and cooling. The thermoelectric cooler is an interesting device that allows the dual functionality such as heating and cooling simultaneously. The thermoelectric cooler (TEC) is also called as peltier cooler. The peltier cooler is a solid state heat pump which uses the peltier effect to move heat.Peltier effect was discovered by Jean peltier in 1934. Peltier effect is a temperature difference created by applying voltage between two electrodes connected to a sample of semiconductor material. Fig.3.Thermo electric cooler/heater C.LM35 temperature sensor: The LM35 sensor is a precision integrated circuit temperature device with an output voltage is linearly proportional to the centigrade temperature. It would be connected to the microcontroller.. As a temperature sensor, the circuit will read the temperature of the surrounding environment, is converted from binary to decimal via programming of the microcontroller which we will be able to read from the computer of the Arduino serial monitor. Here two temperature sensors are used for sensing internal and external temperature of the suit. This is achieved through the code loaded into the Arduino Uno board. D.Relay: A Relay is acts as a switch. Relays are used to control the circuit with low power signal or several circuits must be controlled by one signal. In this circuit we are using a Double Pole Double Throw (DPDT) relay.It has 2 terminals and 4 connectors. A $12 \mathrm{~V}$ battery is connected to relay and applying the load such as TEC across the relay. When internal temperature sensor is greater than potentiometer value then the TEC will becomes cool. Otherwise the relay switches the load. Then the TEC will becomes hot.

When an electric current is made to flow through a junction between two conductors, heat flux is generated at the junction. This phenomenon is known as Peltier effect. Accordingly, a Peltier or thermoelectric device transfers heat from one side of the device to the other side with consumption of electrical energy $[12,13]$. The Peltier devices can be used as a heater or a cooler but they are mostly used in cooling applications. Efficiency of these devices are considerably lower than that of conventional compressor-based cooling systems. Peltier devices operate at about $10 \%$ efficiency, whereas efficiency of a compressor-based refrigerator is about $30 \%$.

DHT11 is a Humidity [14] and Temperature Sensor, which generates calibrated digital output. DHT11 can be interface with any microcontroller like Arduino,. and get instantaneous results. DHT11 is a low cost humidity and temperature sensor which provides high reliability and long term stability. In this paper, we will build a small circuit to interface Arduino with DHT11 Temperature and Humidity Sensor. One of the main applications of connecting DTH11 sensor with Arduino is weather monitoring. The DHT11 detects water vapor by measuring the electrical resistance between two electrodes. The humidity sensing component is a moisture holding substrate with electrodes applied to the surface. When water vapor is absorbed by the substrate, ions are released by the substrate which increases the conductivity between the electrodes. The change in resistance between the two electrodes is proportional to the relative humidity. Higher relative humidity decreases the resistance between the electrodes, while lower relative humidity increases the resistance between the electrodes. 
The DHT11 measures temperature with a surface mounted NTC temperature sensor (Thermistors) [9] built into the unit (Figure 6). To learn more about how thermistors work and how to use them on the Arduino, check out our Arduino Thermistors Temperature Sensor Tutorial. An IC mounted on the back of the unit converts the resistance measurement to relative humidity. It also stores the calibration coefficients, and controls the data signal transmission between the DHT11 and the Arduino:

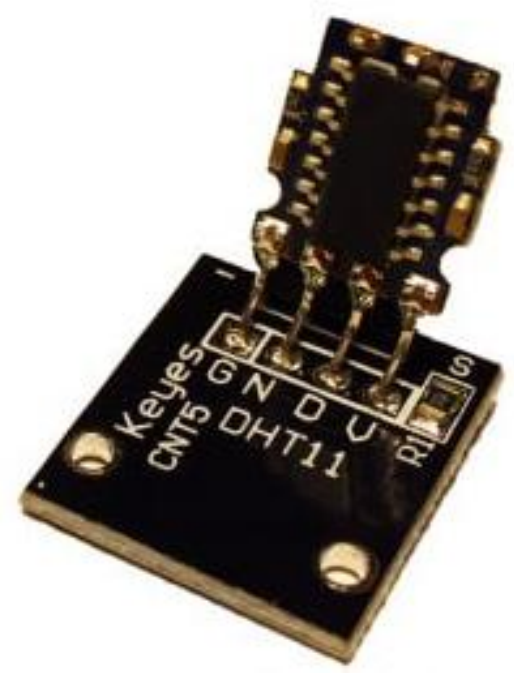

Figure 6. Temperature sensor

The DHT11 uses just one signal wire to transmit data to the Arduino. Power comes from separate $5 \mathrm{~V}$ and ground wires. A $10 \mathrm{~K}$ Ohm pull-up resistor is needed between the signal line and $5 \mathrm{~V}$ line to make sure the signal level stays high by default (see the datasheet for more info). There are two different versions of the DHT11 you might come across. One type has four pins, and the other type has three pins and is mounted to a small PCB. The PCB mounted version is nice because it includes a surface mounted 10K Ohm pull up resistor for the signal line. Here are the pin outs for both versions as shown in Figure 7.
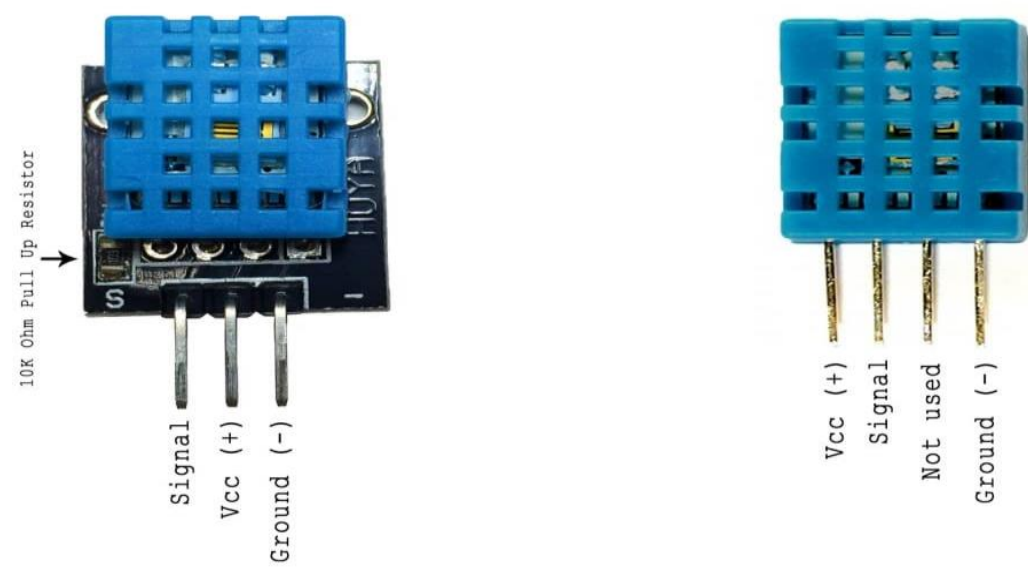

Figure 7. Humidity sensor

\subsection{Software description}

Embedded $\mathrm{C}$ is a set of language extensions for the $\mathrm{C}$ Programming the $\mathrm{C}$ standards committee to address commonality issues that exist between $\mathrm{C}$ extensions for different embedded systems. Historically, embedded $\mathrm{C}$ programming requires nonstandard extensions to the $\mathrm{C}$ language in order to support exotic

Water condensation system based on thermoelectric coller using solar energy (A. N. Abirami) 
features such as fixed point arithmetic, multiple distinct memory banks and basic input output operations. In 2008, the C Standards Committee extended the C language to address these issues by providing a common standard for all implementations to adhere to. It includes a number of features not available in normal $\mathrm{C}$, such as, fixed-point arithmetic, named address spaces, and basic I/O hardware addressing. Embedded $\mathrm{C}$ use most of the syntax and semantics of standard C, e.g., main () function, variable definition, data type declaration, conditional statements (if, switch. case), loops (while, for), functions, arrays and strings, structures and union, bit operations, macros, unions etc. The following is a code program.

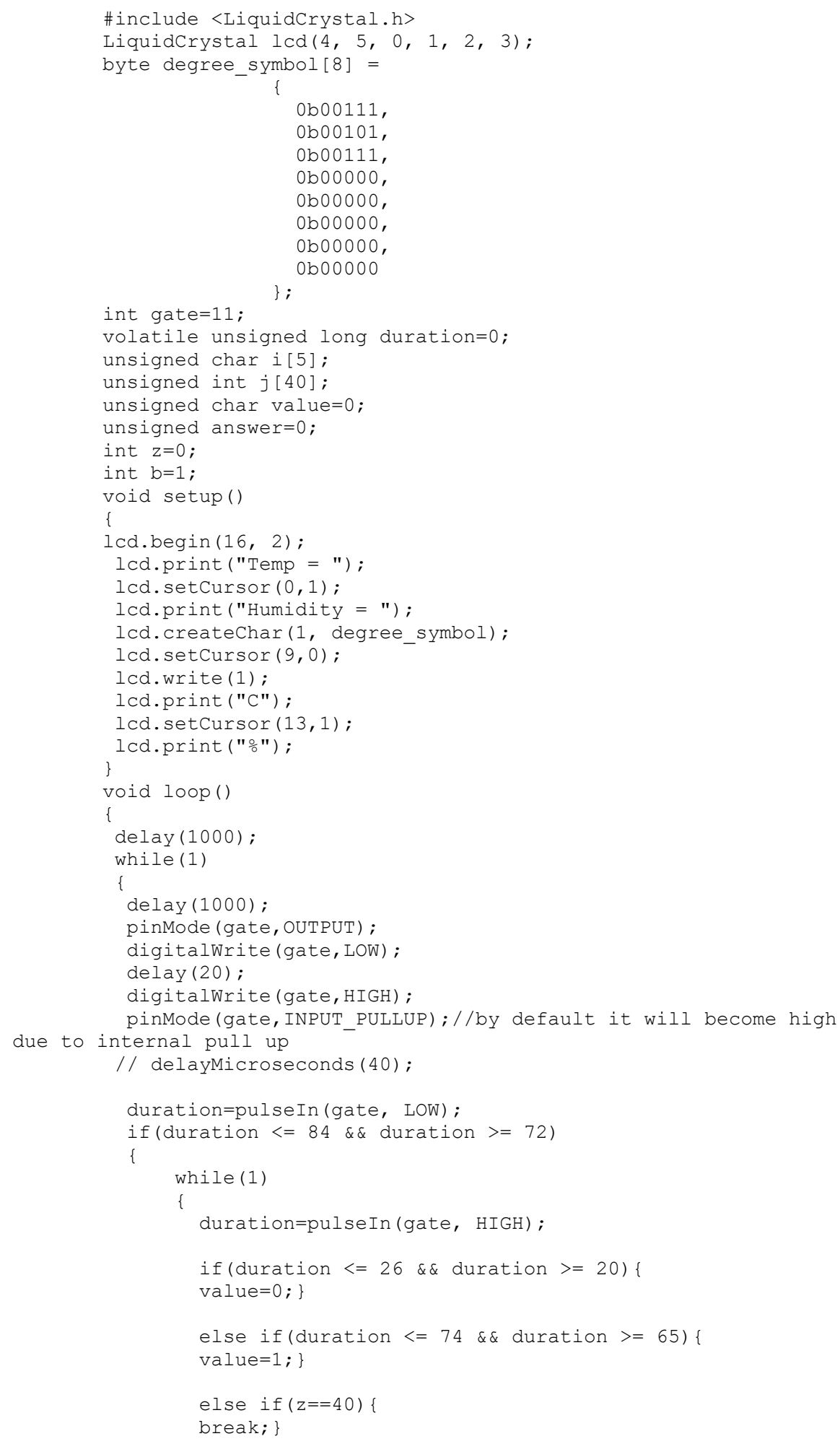




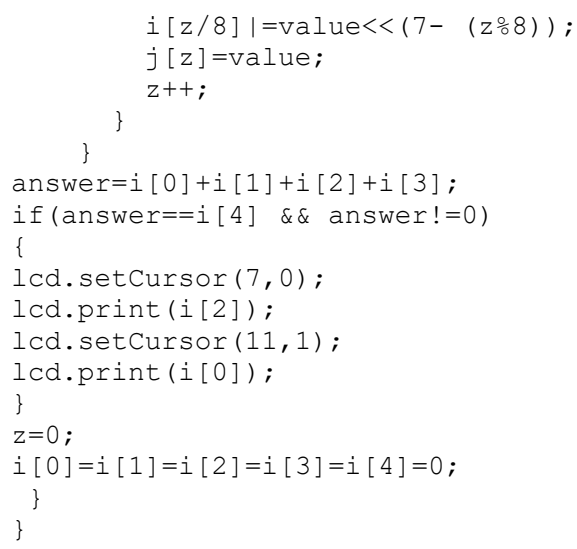

\section{CONCLUSION}

Applying this system in a highly humid region almost 1 Litre of condensed water can be produced per hour during the day light, this is a promising result; then a more enhanced system can be designed that encounters higher power solar cells and also has the adroitness to store the excess energy during the day light that is to be used at night; indeed the economical advantage of this kind of system is a bit obscure due to the relatively high installation cost. This idea can be extended further in future - For large scale implementation, RO and UV water filter can be used for producing such water that meets the standard of WHO and BIS easily. Peltier device has many types of models which are much efficient than TEC1. Those can be used. As the paper aims at producing water from atmosphere and keeping this device handy, large sized scrubbers are not used for better air filtration. Scrubbers can remove all the oxides from the air. For large implementation it can be handled. The concept of this paper can also be used as a better alternative in refrigeration science against conventional systems. It can also be observed in this way i.e. the usage of such low power semiconductor devices are indicating towards more prominent evolution of cooling engineering that is going to alter the whole scenario and myths about the power consumption of refrigeration science. Thus in near future we will be able to use such devices that are now limited within the paper.

\section{FUTURE SCOPE}

Presently, only two Peltier devices in the prototype. In the future the prototype may incorporate another two Peltier devices so as to increase the water output. For giving the prototype an environmental friendly flavour it may include a solar power source (solar panel) in place of the present AC power source without much modifications in the circuitry.

\section{REFERENCES}

[1] Greg M.Peters, Naomi J.Blackburn, Michael Armedion, "Environmental assessment of air to water machinestriangulation to manage scope uncertainity," Springer-Vsuccumbed Berlin Ileidelberg, vol.18, pp. 1149-1157, 2013.

[2] M.A.Muñoz-García, Miguel Angel, Moreda Cantero, P.Guillermo, M.P.Raga Arroyo, Manuela Pilar, Marín González, Omar, "Water harvesting for young trees using Peltier modules powered by photovoltaic solar energy," Computers and Electronics in Agriculture, vol.93, pp.60- 67, 2013.

[3] R.A.Taylor and G.L.Solbrekken, "Comprehensive system-level optimization of thermoelectric devices for electronic cooling applications, components and packaging technologies," IEEE Transactions on Components and Packaging Technologies, vol. .31, no.1, pp. 23-31, 2008.

[4] H.Morimitsu, E.Saito, S.Katsura, "An approach for heat flux sensor-less heat inflow estimation based on distributed parameter system of Peltier device," IECON 2011 - 37th Annual Conference on IEEE Industrial Electronics Society, pp. 4214-4219, 2011.

[5] Rao Y.V.C, An Introduction to Thermodynamics. (2nd ed.), Universities Press, 2003.

[6] Perry R.H and Green D.W., Perry's Chemical Engineers, Handbook. McGraw-Hill, 1984.

[7] Siegfried Haaf, Helmut Henrici, Refrigeration Technology in Ullmann's Encyclopedia of Industrial Chemistry, Wiley-VCH, 2002.

[8] Dixon S.L., Fluid Mechanics, Thermodynamics of Turbomachinery (Third ed.), Pergamon Press, 1978.

[9] Amjed Ginawi and Yan Yunjun, "Molecular techniques applied to investigations of abundance of the ammonia oxidizing bacteria and ammonia oxidizing archaea microorganisms in the environment," International journal of Advances in applied science, vol.8, no.1, pp. 1-7, 2019.

[10] Kabeela A.E, Abdulazizb M., Emad M.S., "Solar-based atmospheric water generator utilisation of a fresh water recovery: A numerical study," International journal of ambient energy, vol. 37, no.1, pp.68-75, 2016. 
[11] Brown, D.R., Fernandez N., Dirks J.A., Stout T.B., "The prospects of alternatives to vapor compression technology for space cooling and food refrigeration applications, Pacific Northwest National Laboratory (PNL). U.S. Department of Energy, 2010.

[12] Jyoti U and Devkota, "A categorical data analysis of impact of biogas on women of rural households-with examples from Nepal," International journal of Advances in applied science, vol.8, no.1, pp. 34-43, 2019.

[13] Satyabrat Kar, N et al., "Effect of chemical reaction on MHD flow with heat and mass transfer past a vertical porousplate in the presence of viscous dissipation," International journal of Advances in applied science, vol.8, no.1, pp. 83-94, 2019.

[14] Anbarasu T and Pavithra S., "Vapour compression refrigeration system generating fresh water from humidity in the air, International Conference on Sustainable Energy and Intelligent Systems (SEISCON 2011), 2011.

\section{BIOGRAPHIES OF AUTHORS}
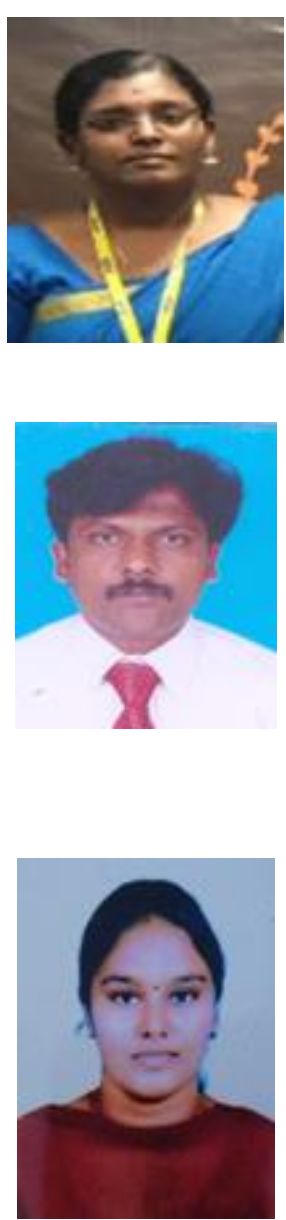

Mrs. A.N.Abirami was born in Karaikudi. She has obtained B.E (Electrical and Electronics) and M.E (Power Electronics and Drives) degrees in 2014 and 2016 respectively. She has been working in the teaching field for about 4 years. Her areas of interest includes power electronics and drives. He has 2 publications in international journals. Her research papers 2 have been presented in various international/national conferences. Currently, she is working as Assistant Professor in the Department of EEE, PERI Institute of Technology, Chennai.
Dr. C.R. Balamurugan was born in Kumbakonam. He has obtained B.E (Electrical and Electronics), M.E (Power Electronics and Drives) and Ph.D (Instrumentation EngineeringPower Electronics) degrees in 2000, 2005 and 2015 respectively. He has been working in the teaching field for about 15 years. His area of interest includes power electronics, electrical machines and solar energy systems. He has 110 publications in international journals. His research papers 80 have been presented in various/IEEE international/national conferences. Currently, he is working as Professor in the Department of EEE, Karpagam College of Engineering, Coimbatore. He is guiding $8 \mathrm{Ph} . \mathrm{D}$ scholars under Anna University, Chennai. He got best faculty awards six times. He has written more than thirty text books. He is the reviewer for many reputed journals. He is a life member of Indian Society for Technical Education and Institute of Engineers. He is a member in IEEE, MIAENG, MUACEE, MIASTER and MISRD.

Mrs. D.Meena was born in Chidambaram. She has obtained B.E (Electrical and Electronics) and M.E (Power Electronics and Drives) degrees in 2007 and 2010 respectively from Annamalai University, Chidambaram and Arunai Engineering College, Tiruvannamalai. She has been working in the teaching field for about 6 years. Her area of interest includes power electronics, electrical machines and solar energy systems. She has 2 publications in international journals. Her research papers 6 have been presented in various international/national conferences. Currently, she is working as Assistant Professor in the Department of EEE, Krishnasamy College of Engineering and Technology, Cuddalore. She is a life member of Indian Society for Technical Education. E-mail: meenadhandapani86@gmail.com. 